\title{
Representação do Conhecimento por Meio de Mapas Conceituais no Domínio do T-Governo
}

\section{Knowledge representation through conceptual maps in the T-government field}

\begin{abstract}
Resumo: O termo ciência cognitiva começou a ser amplamente empregado a partir da década de 1970 . Por meio do estudo das atividades mentais, a ciência cognitiva busca responder questões epistemológicas relativas à natureza do conhecimento, seus componentes, suas origens, seu desenvolvimento e seu emprego, utilizando-se de representações. A partir de um levantamento bibliográfico sobre as possíveis formas de representação de conhecimento, este artigo busca organizar o conhecimento concernente a um serviço de governo eletrônico a ser disponibilizado para o cidadão via TV Digital. Como resultado desta pesquisa, foi possível comprovar a eficiência dos mapas conceituais quando na organização e representação do conhecimento envolvido neste domínio de aplicação. Dentre as diversas vantagens apontadas para a utilização de mapas conceituais para este fim, a simplicidade de organização e entendimento da estrutura de conhecimento é certamente a mais evidente.
\end{abstract}

Palavras-chave: Representação do conhecimento. Mapas conceituais. TV Digital. Governo eletrônico.

\begin{abstract}
The term cognitive science began to be widely used from the 1970s. Through the study of mental activity, the cognitive science seeks to answer epistemological questions related to the nature of knowledge, its components, origins, development and employment, using representations. From a literature survey on the possible ways of representing knowledge, this article aims to organize the knowledge related to an electronic government service to be available to the citizens via digital TV. As a result of this research, it was possible to prove the effectiveness of concept maps when organizing and representing the knowledge involved in this domain. Among the many advantages cited for the use of concept maps for this purpose, simplicity of organization and understanding of the structure of knowledge is certainly the most obvious.
\end{abstract}

Keywords: Knowledge representation. Conceptual maps. Digital TV. Electronic government.

SANTOS, Paloma Maria; ZANCANARO, Airton; SANTOS, Neri dos. Representação do Conhecimento por Meio de Mapas Conceituais no Domínio do T-Governo. Revista Informática na Educação: teoria e prática, Porto Alegre, v. 18, n. 1, p. 147-160, jan./jun. 2015.
Paloma Maria Santos

Airton Zancanaro

\section{Introdução}

\author{
Neri dos Santos \\ Universidade Federal de Santa Catarina
}

A s ciências cognitivas ou ciências da cognição, por meio dos seus campos de pesquisa constituintes, quais sejam a Filosofia, a Psicologia, a Inteligência Artificial, a Neurociência, a Antropologia e a Linguística objetivam estudar os processos empregados pelos sistemas de tratamento da informação para tomar conhecimento de seu ambiente e modificá-lo.

Entre os seus principais temas aglutinadores estão: a percepção, a linguagem, a aprendizagem, o raciocínio, a memória e a ação. Para explicar tais variedades, as ciências cognitivas se utilizam de representações. 
Estas representações podem ser construídas a partir de diversos processos, quais sejam: esquemas, mapas conceituais, mapas mentais, metáforas e analogias e rede hipertextual de significados. Cada um deles difere entre si pela natureza dos meios empregados e dos resultados obtidos. A utilização de um ou outro processo para a construção de uma representação vai depender da natureza da tarefa a ser executada.

Tendo em vista, organizar o conhecimento concernente a um serviço de governo eletrônico a ser disponibilizado para o cidadão via TV Digital, este artigo busca, em se utilizando de mapas conceituais, representar tal conhecimento.

Para tal, a seção 2 aborda um histórico e os conceitos básicos sobre as ciências da cognição, as diferentes formas de representação e o conhecimento. Na seção 3, apresenta-se os mapas conceituais, sua fundamentação teórica, bem como, os processos para construção de um mapa conceitual. A seção 4 traz a aplicação do mapa conceitual na verificação do nível de água do rio Itajaí-Açú voltado para a TV Digital e finalmente, na seção 5, têm-se as conclusões e as oportunidades de trabaIhos futuros.

\section{Ciências da Cognição: histórico e conceitos básicos}

As ciências cognitivas têm um passado muito longo, mas uma história, de certo modo, relativamente curta. Apesar do campo científico ter sido oficialmente reconhecido em 1956, por ocasião do Simpósio sobre Tecnologia da Informação realizado no Massachusetts Institute of Technology, as raízes das ciências da cognição remontam aos debates dos filósofos gregos acerca da natureza do conhecimento humano.

Para Gardner (1995), o antecessor filosófico prototípico da ciência cognitiva talvez fosse René Descartes que já em 1623, dado desencantamento com os sistemas criados pelos pensadores anteriores, desenvolveu um método de dúvida sistemática que punha em questão toda evidência sobre a qual ele não tivesse certeza. Por meio do exame dos conteúdos de sua própria mente, Descartes acreditava que poderia estabelecer o conhecimento que era mais válido e, portanto, menos sujeito a questionamentos.

A partir da década de 1970, o termo ciência cognitiva começou então a ser amplamente empregado. Diversos cientistas tentaram definir a natureza e o domínio desse campo de estudo, de forma que em 1978, um relatório solicitado pela Fundação Alfred Sloan, como resultado de um programa de investimentos em instituições de pesquisa, elencou as inter-relações entre os seis campos constituintes da ciência cognitiva - o hexágono cognitivo, representado na Figura 1.

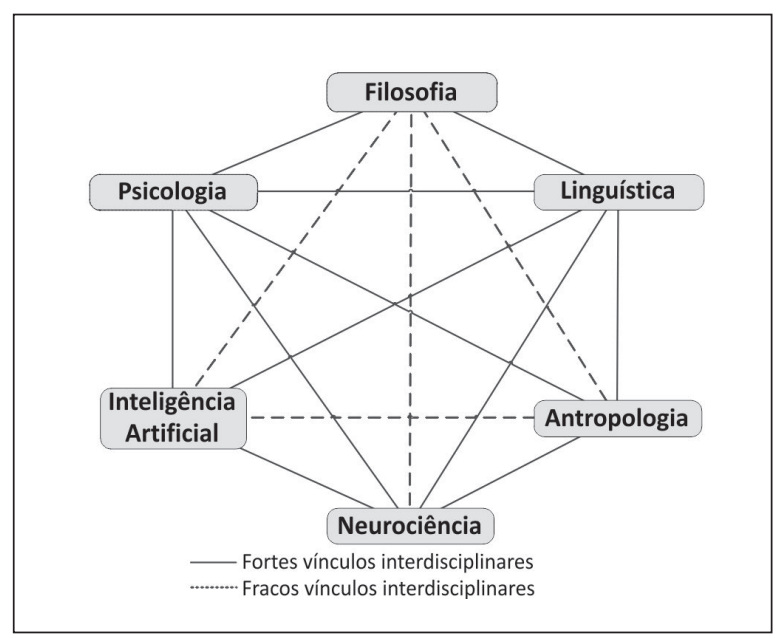

FIGURA 1 - O hexágono cognitivo FONTE: Gardner (1995, p. 52) 
Percebe-se, ao analisar a figura acima, que a ciência da cognição é, em si, transdisciplinar, na medida em que a compreensão do fenômeno cognitivo requer a contribuição de olhares advindos de diversos domínios de conhecimento que, ao combinarem-se, produzem um olhar diferenciado, uma nova episteme (FIALHO, 2011).

A ciência cognitiva está vinculada a um esforço contemporâneo, com fundamentação empírica, que busca responder questões epistemológicas mais antigas - especialmente àquelas relativas à natureza do conhecimento, seus componentes, suas origens, seu desenvolvimento e seu emprego (GARDNER, 1995). Pelo fato desse campo científico ainda não estar bem maduro, não há um consenso entre os pesquisadores sobre o seu conteúdo e seus métodos (LUGER, 1994).

Como alicerce, a ciência cognitiva possui a crença de que é necessário postular um nível de análise separado para explicar a variedade do comportamento, da ação e do pensamento humano. Este nível pode ser chamado de nível da representação (GARDNER, 1995).

\subsection{Representação e Conhecimento}

Representações, segundo Fialho (2011, p. 65), são interpretações que "[...] utilizam conhecimentos para atribuir um significado de conjunto aos elementos resultantes da análise perceptiva, isto no contexto de uma situação e de uma tarefa particular [...]".

Apesar de serem bastante particularizadas, transitórias e precárias, as representações desempenham um papel central na elaboração de decisões, uma vez que são as únicas informações concernentes à situação e à tarefa a partir das quais são elaboradas as decisões de ação. Sua construção compor- ta a seleção e a atribuição de significados os elementos percebidos. Assim, podemos dizer que as representações são instâncias das estruturas de conhecimentos existentes (FIALHO, 2011).

O conhecimento inclui familiaridade, sensibilização e compreensão (NHS, 2005). Mais do que isso, o conhecimento envolve a capacidade contínua de agir (SVEIBY, 1998), envolve uma construção cognitiva permanente. Quanto o indivíduo aprende, mais ele melhora essa representação.

Para Dupuy (1996, p. 27), "[...] todo conhecimento é reprodução, representação, repetição e simulação [...]". Sendo que, do ponto de vista do funcionamento cognitivo, a diferença entre conhecimento e representação - segundo Fialho (2011), é que o conhecimento, para ser eficiente precisa ser ativado, enquanto a representação é imediatamente eficiente. Além disso, o conhecimento, assim como a representação, também é uma construção, porém é permanente e não é inteiramente dependente da tarefa a realizar.

As ciências cognitivas distinguem basicamente dois tipos de conhecimento: o declarativo que representa os conceitos e é a maneira pela qual pensamos os objetos, eventos e ideias, e o procedural que é o que sabemos sobre como fazer algo. Estes dois conhecimentos são complementares e não existem em estado puro, havendo a predominância de um ou outro (AMORETTI, 2001).

Enquanto o conhecimento declarativo pode se construir a partir de informações simbólicas veiculadas na aprendizagem em terceira pessoa, como textos, por exemplo; o conhecimento procedural se constrói pela ação, aprendizagem em primeira pessoa, a partir da resolução de problemas. Um corresponde a uma aprendizagem por instrução, onde a internalização acontece por repetição e, o ou- 
tro, a uma aprendizagem por descoberta. Por meio da repetição, adquirimos competências. Já por meio da ação, transformamos competências em habilidades (FIALHO, 2011).

Tanto o conhecimento declarativo quanto o procedural são tidos como gerais e constituem a memória semântica, que segundo Matlin (2004), é a que descreve nosso conhecimento organizado sobre o mundo, abarcando o conhecimento das palavras e de outras informações não pessoais.

A memória semântica, assim como a memória episódica, que se refere a lembranças de eventos acontecidos conosco, e a memória procedural, que vincula o conhecimento que temos sobre o modo de fazer alguma coisa, são subdivisões da memória de longo termo (MLT) (MATLIN, 2004). Essa subdivisão, conforme salienta a autora, reflete a conveniência e não a convicção de que as subdivisões caracterizam sistemas diferentes de memória. Para que determinado conhecimento seja armazenado na MLT, é necessário que alguma emoção esteja associada a esse tipo de conhecimento.

Já na memória de curto termo (MCT), também conhecida como memória de trabalho, as lembranças são frágeis e contém somente a pequena quantidade de informações que estamos usando de maneira ativa, embora não tão frágeis quanto às da memória sensorial, que possui grande capacidade de armazenamento e registra informações de cada um dos sentidos com razoável exatidão (MATLIN, 2004).

Para Fialho (2011), o indivíduo só aprende quando passa o conhecimento da MCT para a MLT, sendo que a aprendizagem pode se dar de três maneiras:
- Aprendizagem integrada: quando o indivíduo muda o modelo mental e o comportamento;

- Aprendizagem forçada: quando o indivíduo muda o modelo mental, mas não muda o comportamento;

- Aprendizagem frustrada: quando o indivíduo muda comportamento, mas não muda o modelo mental.

\subsubsection{Diferentes formas de representa- ção}

Fialho (2011), baseado nos trabalhos de Jean-François Richard e Pierre Lèvy, distingue vários processos de construção de representações, que têm o mesmo sentido da palavra compreender. Tais processos podem ser observados no Quadro 1, abaixo.

QUADRO 1 - Diferentes Processos de Construção de Representação

\begin{tabular}{|l|l|l|}
\hline $\begin{array}{l}\text { Estrutura } \\
\text { Cognitiva }\end{array}$ & \multicolumn{1}{|c|}{$\begin{array}{c}\text { Natureza dos } \\
\text { Resultados Obti- } \\
\text { dos }\end{array}$} & \multicolumn{1}{|c|}{$\begin{array}{c}\text { Natureza dos } \\
\text { Meios Empre- } \\
\text { gados }\end{array}$} \\
\hline Esquemas & $\begin{array}{l}\text { Esquema particulari- } \\
\text { zado a uma situação }\end{array}$ & $\begin{array}{l}\text { Substituir as vari- } \\
\text { áveis do esquema } \\
\text { por elementos da } \\
\text { situação }\end{array}$ \\
\hline $\begin{array}{l}\text { Redes Se- } \\
\text { mânticas }\end{array}$ & $\begin{array}{l}\text { Rede conceitual es- } \\
\text { pecífica à situação }\end{array}$ & Inferências \\
\hline $\begin{array}{l}\text { Mapas } \\
\text { Mentais }\end{array}$ & $\begin{array}{l}\text { Modelo mental par- } \\
\text { ticularizado para a } \\
\text { situação }\end{array}$ & Inferências \\
\hline $\begin{array}{l}\text { Metáforas } \\
\text { e Analo- } \\
\text { gias }\end{array}$ & $\begin{array}{l}\text { Transferência na } \\
\text { aplicação de estru- } \\
\text { turas de um domínio } \\
\text { de conhecimento } \\
\text { para outro }\end{array}$ & Analogia \\
\hline $\begin{array}{l}\text { Rede Hi- } \\
\text { pertextual } \\
\text { de Signifi- } \\
\text { cados }\end{array}$ & $\begin{array}{l}\text { Rede hipertextual } \\
\text { de significados par- } \\
\text { ticularizada a uma } \\
\text { situação }\end{array}$ & $\begin{array}{l}\text { Buscar um centro } \\
\text { e construir uma } \\
\text { nova rede com os } \\
\text { nós associados }\end{array}$ \\
\hline
\end{tabular}

FONTE: Fialho (2011, p. 140) 
Esquemas são estruturas de dados utilizadas para representar a organização dos conhecimentos armazenados na memória (AMORETTI, 2001). A construção de uma representação por meio de um esquema consiste em substituir as variáveis do esquema por elementos específicos da situação. O resultado é um esquema particularizado a uma situação.

Redes semânticas ou mapas conceituais são representações espaciais dos conceitos e suas relações. Elas representam tanto o processo de organização do conhecimento, por meio das relações (links), quanto o produto, por meio dos conceitos (nós) (AMORETTI, 2001). A construção de uma representação por meio de um mapa conceitual emprega, principalmente, inferências e é orientada pelas informações do texto e pela ordem em que estas são fornecidas. O resultado é uma rede conceitual específica à situação.

Mapas mentais são uma abstração das percepções e experiências que guiam nossas decisões (MEADOWS et al., 1974). São profundamente baseados em suposições, generalizações ou mesmo imagens que influenciam como nós entendemos o mundo e como nós agimos (SENGE, 1990). A construção de uma representação por meio de um mapa mental também emprega inferências e o resultado é uma imagem de situação.

Metáfora é a comparação implícita da estrutura de dois domínios, destacando características ou qualidades relacionais que não coincidem. Já a analogia é a comparação explícita, que indica semelhança ou identidade de partes das estruturas (DUIT, 1991). A construção de uma representação por meio da analogia recorre, principalmente, à memória e é conduzida pelos conhecimentos. 0 resultado é a transferência na aplicação de estruturas de um domínio de conhecimento para outro.

A rede hipertextual de significados se configura através de conceitos e relações hierárquicas estabelecidas entre eles. Assim como as redes semânticas, as redes hipertextuais de significados operam através de inferências e representam formas de compreender. Enquanto as redes semânticas se caracterizam por redes conceituais específicas a uma situação, as redes hipertextuais de significados são parte da rede particularizada a uma situação (CORRADI et al., 2001).

Esses processos diferem entre si pela natureza dos meios empregados e dos resultados obtidos. A utilização de um ou outro processo para a construção de uma representação vai depender da natureza da tarefa a ser executada.

Okada (2008) corrobora com Fialho (2011) e apresenta o termo Cartografia Cognitiva, apontando alguns tipos de mapas existentes, apresentados no Quadro 2, tendo como objetivo organizar o saber como forma de selecionar o que é relevante em meio a tanta informação existente atualmente.

\section{QUADRO 2 - Mapeamento da Cartografia Cognitiva}

\begin{tabular}{|c|c|}
\hline TIPO & DEFINIÇÃO \\
\hline $\begin{array}{l}\text { Mapas } \\
\text { Conceitu- } \\
\text { ais }\end{array}$ & $\begin{array}{l}\text { Representação de conceitos e suas rela- } \\
\text { ções por meio de ligações hierárquicas } \\
\text { descritas por palavras que determinam } \\
\text { sentenças ou proposições válidas esta- } \\
\text { belecendo assim um significado dentro } \\
\text { de certo domínio de conhecimento (No- } \\
\text { vak, 1998) }\end{array}$ \\
\hline $\begin{array}{l}\text { Mapa Men- } \\
\text { tal }\end{array}$ & $\begin{array}{l}\text { Representação de ideias que emergem } \\
\text { por meio de palavras-chave e suas asso- } \\
\text { ciações envolvendo texto, imagem, co- } \\
\text { res e conexões espaciais com objetivos } \\
\text { de visualizar, classificar e gerar ideias, } \\
\text { ou estudo, resolução de problemas e to- } \\
\text { mada de decisão (Buzan, 2000) }\end{array}$ \\
\hline
\end{tabular}




\begin{tabular}{|l|l|}
\hline $\begin{array}{l}\text { Mapa Ar- } \\
\text { gumenta- } \\
\text { tivo }\end{array}$ & $\begin{array}{l}\text { Representação de raciocínio composto } \\
\text { por uma constelação de pressupostos, } \\
\text { razões e objeções que vão constituindo } \\
\text { argumentos visando esclarecer um de- } \\
\text { terminado assunto (Van Gelder, 2004) }\end{array}$ \\
\hline $\begin{array}{l}\text { Mepresentação da discussão por meio de } \\
\text { um conjunto de questões ou problemas, } \\
\text { possíveis soluções, respostas, prós e } \\
\text { contras, anotações, referências e conclu- } \\
\text { sões ou decisões. A conversa é orientada } \\
\text { e configurada por meio da visualização } \\
\text { do próprio mapa que representa o diálo- } \\
\text { go (Conklin, 2006) }\end{array}$ \\
\hline Mapa Web & $\begin{array}{l}\text { Representações digitalizadas hipertextu- } \\
\text { ais que representam redes de informa- } \\
\text { ções e documentos da internet (Chen, } \\
\text { 2003, Kitchin; Dodge, 2001) }\end{array}$ \\
\hline $\begin{array}{l}\text { Mapa de } \\
\text { Dados }\end{array}$ & $\begin{array}{l}\text { Representações de dados multidimensio- } \\
\text { nais que permitem visualizar, organizar, } \\
\text { construir modelos e explicar fenômenos } \\
\text { associados aos dados (Almouloud, 2008) }\end{array}$ \\
\hline $\begin{array}{l}\text { Multidi- } \\
\text { mensionais }\end{array}$
\end{tabular}

FONTE: Adaptado de Okada (2008)

Para tal, opta-se neste trabalho pelo uso dos mapas conceituais como forma de sistematizar o conhecimento significativo dentro de um domínio específico que é o de governo eletrônico.

\section{Mapas Conceituais e sua Funda- mentação Teórica}

Entre os significados do termo mapa, encontra-se a conotação de representação, diagrama ou lista descritiva (HOUAISS et al., 2009). Mapa é uma das formas mais antigas de representação e comunicação gráfica. Eles antecedem o surgimento da escrita e do sistema numérico e atualmente são considerados como importantes ferramentas gráficas para classificar, representar e comunicar os diferentes elementos de qualquer área do conhecimento (OKADA, 2008). Os mapas, quando bem desenhados, possibilitam descobrir novos atalhos e estabelecer novas conexões.
Já a palavra conceitual, refere-se a um sentido próximo ao abstrato ou teórico, ou ainda, uma construção elaborada pela inteligência (DORON; PAROT, 1998). Desta forma, pode-se dizer que os mapas conceituais têm a finalidade de ser legível e permitir ser explorado com pouco texto, deixando claro para o aprendiz o conteúdo a ser aprendido.

$\mathrm{Na}$ continuidade deste artigo, serão abordadas a fundamentação teórica que envolve os mapas conceituais. Para isso, inicia-se com um breve relato sobre a teoria da aprendizagem significativa desenvolvida por David $\mathrm{P}$. Ausubel e posteriormente os mapas conceituais.

\subsection{Aprendizagem Significativa}

A teoria cognitivista desenvolvida por Ausubel, teve sua concepção nos anos 60, no qual a aprendizagem significativa encontra-se entre as primeiras propostas que tentaram explicar o processo de aprendizagem escolar a partir de um afastamento dos princípios behavioristas ${ }^{1}$.

A psicologia da cognição (cognitivismo) é um ramo da psicologia que estuda a cognição e os processos mentais que estão ligados ao conhecimento, sendo assim, a forma como o indivíduo percebe e aprende. Ela preocupa-se com a percepção, o pensamento e a memória, procurando explicar como o ser humano percebe o mundo e como utiliza-se do seu conhecimento para desenvolver diversas funções cognitivas como: falar, raciocinar, resolver problema, memorizar, entre outras (MOREIRA; MASINI, 2002, MOREIRA, 2005).

\footnotetext{
1 "Para o behaviorismo, as respostas do organismo têm uma função adaptativa e constituem reações às mudanças do meio. $\mathrm{O}$ organismo aprende a produzir as respostas que Ihe permitem adaptar-se ao meio". (DORON; PAROT, 1998, p. 113)
} 
A ideia central da teoria de Ausubel é da aprendizagem significativa. Uma aprendizagem se diz significativa quando uma nova informação (conceito, ideia ou proposição) adquire significado para o aprendiz (MOREIRA, 2005). É um processo "[...] no qual uma nova informação é relacionada a um aspecto relevante, já existente, da estrutura de conhecimento de um indivíduo [...]" (NOVAK, 1981, p. 56).

De acordo com Pelizzari et al. (2001), para que ocorra aprendizagem significativa são necessárias, em primeiro lugar, a disposição do aprendiz para aprender e em segundo lugar, que o conteúdo a ser aprendido seja potencialmente significativo, possuindo uma estrutura lógica e psicologicamente significativa.

Ausubel baseia a sua teoria na suposição de que o indivíduo pensa com conceitos, 0 que destaca a sua importância para a aprendizagem. Neste caso, um conceito é um termo que "[...] representa uma série de características, propriedades, atributos, regularidades e/ou observação de um objeto, fenômeno ou evento" (MOREIRA, 2005 p.16). Esse processo por meio do qual uma nova informação é acoplada a uma estrutura cognitiva particular e específica é conhecido como subsunçor ${ }^{2}$ (NOVAK, 1981).

Assim, durante a aprendizagem significativa a nova informação é assimilada pelos subsunçores relevantes existentes na estrutura cognitiva do indivíduo. Estes conceitos relevantes, os subsunçores - ou conceitos incorporadores, integradores, inseridores, âncoras - são determinantes para o conhecimento prévio ancorado nas novas aprendizagens, conforme ilustra a Figura 2.

2 Subsunçor surgiu da tradução do termo em inglês subsumer (PELIZZARI et al, 2001).

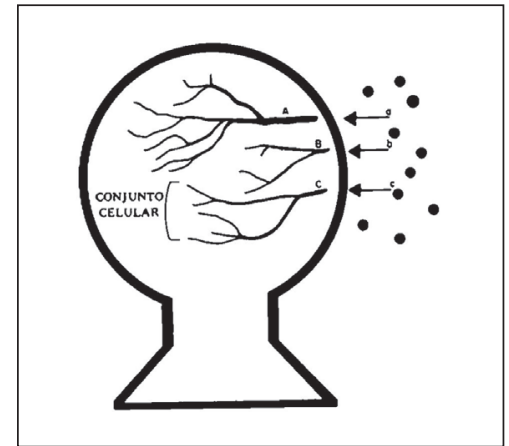

FIGURA 2 - Novas Informações a, b e c são Ligadas aos Subsunçores A, B e C FONTE: Novak (1981, p. 57)

As novas informações a, b e c são ligadas a estrutura do conhecimento já existente (subsunçores) A, B e C. Esta nova aprendizagem significativa resulta em crescimento e modificação de um subsunçor já existente. Dependendo da experiência do indivíduo, os subsunçores podem ser relativamente grandes e bem desenvolvidos, conforme ocorre com $A$ na Figura 2. Por outro lado, o subsunçor B é o que possui menor complexidade.

\subsection{Mapas Conceituais}

Os mapas conceituais tiveram a sua fundamentação teórica na teoria construtivista da aprendizagem significativa criada por David Ausubel. Porém, segundo Moreira (2005), Ausubel nunca falou de mapas conceituais em sua teoria.

O conceito de mapas conceituais foi criado por Joseph Novak e seus colaboradores no Departamento de Educação da Universidade de Cornell nos Estados Unidos na década de 70. Novak focou as suas pesquisas na criação e representação do conhecimento e, atualmente, é professor benemérito da Universidade de Conell, pesquisador e cientista sênior 
do Institute Human \& Machine Cognitition ${ }^{3}$ (IHMC) (IHMC, 2011).

Os mapas em geral são extremamente úteis quando conseguem representar, de forma eficiente, os aspectos do mundo real. Esta fidelidade não é diferente no caso dos mapas conceituais, no qual a função é representar conceitos e ideias e não necessariamente entidades do mundo real. Assim, um mapa conceitual é uma forma de representar o conhecimento, podendo ser um processo, uma parte do mundo real, teorias e conceitos, entre outros (CODINA, 2010).

O mapeamento conceitual, conforme afirma Moreira e Buchweitz (1987, p. 9), "[...] é uma técnica que pode ser utilizada para ilustrar a estrutura conceitual de uma fonte de conhecimentos". Esta ilustração, apresentada pelos autores, é o que se convencionou chamar de mapa conceitual.

Em um sentido amplo, mapas conceituais são diagramas que representam a relação entre os conceitos. Mais especificamente, são diagramas hierárquicos que procuram refletir a estrutura conceitual de uma área do conhecimento (ALMEIDA; MOREIRA, 2008).

Podendo ser apresentados em uma ou mais dimensões, os mapas conceituais têm o objetivo de retratar as relações significativas entre os conceitos na forma de proposições, deixando claras as ideias chaves em que se devem focar na tarefa de aprendizagem (NOVAK; GOWIN, 1999). Apresenta-se inicialmente, no mapa, os conceitos mais abrangentes, sendo progressivamente relacionados os conceitos mais específicos.

Nos mapas unidimensionais são listados apenas os conceitos de forma simplificada no qual a tendência é a organização ser vertical. Já os bidimensionais são mais simples e fami-

\footnotetext{
${ }^{3}$ Endereço eletrônico: <http://www.ihmc.us/>.
}

liares, permitindo uma melhor representação dos conceitos por meio de linhas que os ligam.

Assim, Moreira e Buchweitz colocam que talvez a melhor definição para os mapas conceituais seja: "[...] diagramas bidimensionais que procuram mostrar conceitos hierarquicamente organizados e as relações entre esses conceitos de uma fonte de conhecimentos e derivam sua existência da própria estrutura fonte $[\ldots]^{\prime \prime}$ (MOREIRA; BUCHWEITZ, 1987, p. 11). A estrutura de um mapa conceitual hierarquizada, na qual Moreira e Buchweitz se referem, pode também ser representada na forma radial ou em árvore tendo sempre um único nodo principal.

Os mapas conceituais requerem pelo menos um conjunto de nodos e um conjunto de arcos conforme apresentadas na Figura 3. Os nodos são conceitos ou entidades representadas num diagrama. Todos os nodos devem estar rotulados com nomes substantivos simples ou compostos, ou seja, o que é importante representar nos nodos de forma consistente. Já um arco é uma representação de uma relação entre os nodos que podem ou não ser rotulados. Quando estão rotulados, o texto deve consistir de um verbo ou uma expressão verbal que torna evidente a relação entre os nodos.

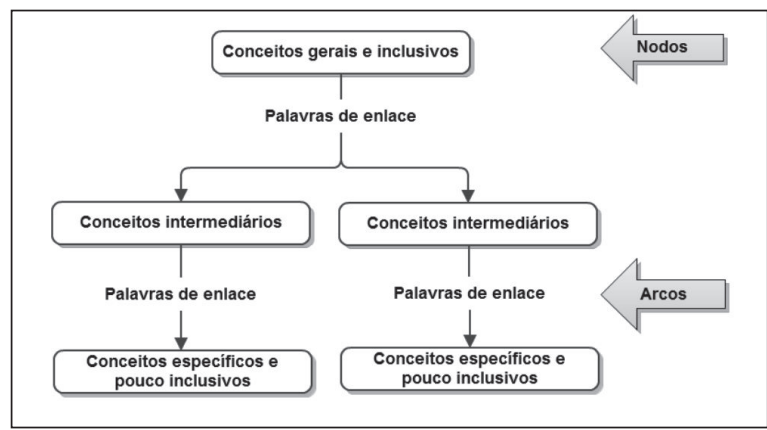

FIGURA 3 - Possibilidade de Estruturação do Mapa Conceitual

FONTE: Elaborada pelos próprios autores. 
Os conceitos são escolhidos pelo indivíduo em razão da sua representatividade cultural. Por este motivo, mapas construídos por especialistas de uma mesma área, muito provavelmente refletirão algumas diferenças de compreensão e interpretação. Estes conceitos indicam ainda, um conjunto de características a que pertencem os objetos de uma determinada classe, para um determinado segmento social, permitindo deste modo, distingui-los de todos os outros (AMORETTI; TAROUCO, 2008).

O processo de construção de um mapa conceitual envolve etapas como: a escolha do assunto e identificação das palavras-chave ou frases relacionadas; organização de conceitos do mais abstrato para o mais concreto; agrupamento dos conceitos em um mesmo nível de abstração e com forte relacionamento; organização dos conceitos na forma de um diagrama; conexão dos conceitos com linhas utilizando palavras de enlace (LIMA, 2004).

As vantagens dos mapas conceituais apontadas por Lima são:

a) Definição de uma ideia central, através do posicionamento do assunto no centro do diagrama;

b) Clara indicação da importância relativa da ideia;

c) Facilidade para encontrar os links entre as ideias-chaves;

d) Visão geral de toda a informação básica numa mesma página;

e) Renovação e revisão mais eficientes;

f) Inserção de novas informações sem atrapalhar a estrutura informacional;

g) Facilidade de compreensão da complexidade de relações entre as ideias;

h) Facilidade para verificar contradições, paradoxos e falhas no material organizado. (LIMA, 2004, p. 140)
Para auxiliar no processo de confecção dos mapas, o IHMC desenvolveu o CMAPTools ${ }^{4}$ (CAÑAS et al., 2004), um software de licença gratuita que provê uma série de recursos computacionais de modo a simplificar, enriquecer e aperfeiçoar a experiência de modelagem desses mapas. Além deste, outro software que pode ser destacado é o Compendium ${ }^{5}$, desenvolvido pela Open University no qual a sua finalidade é de mapear informações, ideias e argumentos.

Tendo em vista representar o conhecimento por meio de mapas conceituais, a seção que segue apresenta uma aplicação no domínio do governo eletrônico, considerando a sua modelagem voltada para a TV Digital.

\section{Mapa Conceitual da Verificação do Nível de Água do Rio Voltado Para a TV Digital}

O desenvolvimento de programas de governo eletrônico tem como princípio a utilização das Tecnologias de Informação e Comunicação (TICs) em prol da democratização do acesso à informação, da ampliação de discussões e da dinamização da prestação de serviços públicos aos cidadãos, com foco na eficiência e efetividade das funções governamentais (BRASIL, 2010).

O governo eletrônico busca fortalecer a participação da sociedade civil por meio do acesso a informações e serviços de forma eletrônica, visando dar mais agilidade aos processos e transformando a relação com os cidadãos. Segundo Sanchez (2003), o intuito do governo eletrônico também congrega a implementação de valores democráticos, como

\footnotetext{
${ }^{4}$ Endereço eletrônico: <http://cmap.ihmc.us/>.

${ }^{5}$ Endereço eletrônico: <http://compendium.open.ac.uk/>.
} 
a participação, a transparência, a atenção à dignidade humana, a representatividade e o controle, pela sociedade, sobre os agentes públicos.

Nesse contexto, qualquer esforço do governo eletrônico deve ter como prioridade a promoção da cidadania, que, de acordo com Marshal (1967), engloba um conjunto de valores sociais que vai desde o direito a um mínimo de segurança e bem-estar econômico, ao direito de participar e intervir na herança social e política do país.

A promoção da cidadania está entre as diretrizes gerais do governo eletrônico e se faz exercer por meio da democratização do acesso as TICs, prerrogativa da inclusão digital. Hoje, mais do que nunca, esse acesso é uma pré-condição para a participação social, econômica e cívica do cidadão. A acessibilidade envolve ainda as habilidades e competências para entender e manipular os espaços eletrônicos criados pelas novas mídias (SOURBATI, 2004).

A TV Digital, que vem sendo implantada no Brasil desde 2007, traz abarcadas as promessas do governo com relação à inclusão social, principalmente dos menos favorecidos. Como maior promessa da migração do sistema televisivo, o Governo prevê a inclusão social, através da inclusão digital. A televisão, que na maioria dos casos é a única fonte de informação e entretenimento do cidadão, apresenta-se como uma ferramenta através da qual essa inclusão pode se tornar realidade.

As iniciativas de governo eletrônico devem estar direcionadas ao atendimento das reais necessidades dos cidadãos, priorizando o fornecimento de serviços integrados e seguros em um ambiente interativo.

Assim, este artigo tem como foco a modelagem de um serviço de governo voltado para a TV Digital, atendendo as necessidades dos moradores do município de Blumenau, cidade localizada a nordeste do estado de Santa Catarina, que possui uma população de cerca de 300 mil habitantes.

\subsection{Descrição do Serviço}

Fundada em 1850, Blumenau tem na atividade industrial e na produção de software suas principais economias. Por estar localizada no vale do rio Itajaí-Açú, Blumenau está à mercê de enchentes que, por algumas vezes, já devastaram a cidade. A última ocorreu em 2008 e proporcionou muitas mortes e prejuízos à população.

Oferecer um serviço que informe aos moradores o nível do rio e a possibilidade de verificar se a sua rua está em perigo de alagamento, vai ao encontro dos preceitos do governo eletrônico.

Atualmente as informações sobre o nível do rio Itajaí-Açú estão disponíveis apenas na Internet. Além disso, o cidadão tem no carnê de IPTU a informação sobre a cota-enchente por ruas. Para saber se a sua rua corre risco de alagamento, o indivíduo necessita comparar o que diz no carnê com a informação do nível do rio.

A partir da cheia ocorrida em 1992, foi realizado um trabalho de atualização das cotas de enchente da área urbana, com o objetivo de informar e orientar melhor a população blumenauense situada em zonas sujeitas às inundações.

A cota-enchente difere da cota topográfica do IBGE, pois se relaciona diretamente com os níveis das águas, medidos a partir de sensores instalados ao logo do rio. A coleta das informações é realizada a cada hora e os dados são armazenados no banco de dados da Defesa Civil, e esta, por sua vez, toma as 
medidas cabíveis sempre que necessário.

Ao transportar este serviço para a TV Digital, o cidadão poderá obter via televisão a informação sobre o nível do rio juntamente com um histórico das últimas 5 horas. Além disso, ele terá a possibilidade de verificar se a sua residência encontra-se em risco de alagamento. Para isso, ele informará ao sistema disponível via televisão o CEP da sua rua, para que este, então, retorne com as informações sobre a cota de enchente e o risco de alagamento, dizendo se a situação é normal, de atenção, de alerta ou de emergência.

As regras quanto ao nível do rio são as seguintes: Normal, quando está abaixo de 4 metros; Atenção, quando está entre 4 e 6 metros; Alerta, de 6 a 8,5 metros; e Emergência, acima de 8,5. O sistema informa ainda o abrigo mais próximo ao CEP informado, para os casos de emergência.

As informações acima descritas são organizadas e apresentas ao cidadão conforme demonstrado no Quadro 3.

QUADRO 3 - Apresentação dos Dados na Tela da TV

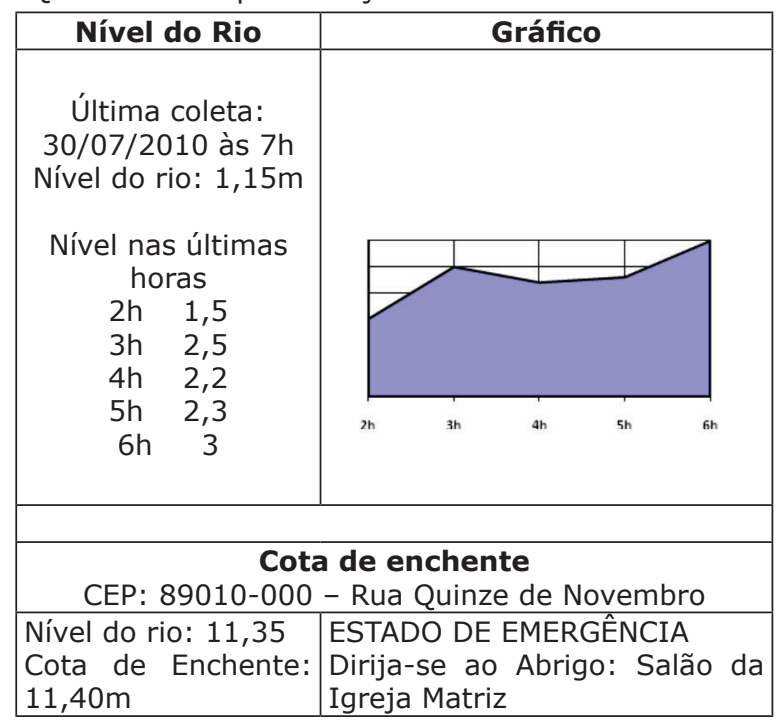

FONTE: Elaborado pelos próprios autores.
De posse destas informações, o cidadão poderá se precaver de quaisquer eventualidades em casos de emergências.

\subsection{Representação do Serviço por Meio de Mapa Conceitual}

Na sequência, apresenta-se o mapa conceitual do sistema modelado para auxiliar o cidadão em épocas de enchente, conforme Figura 4.

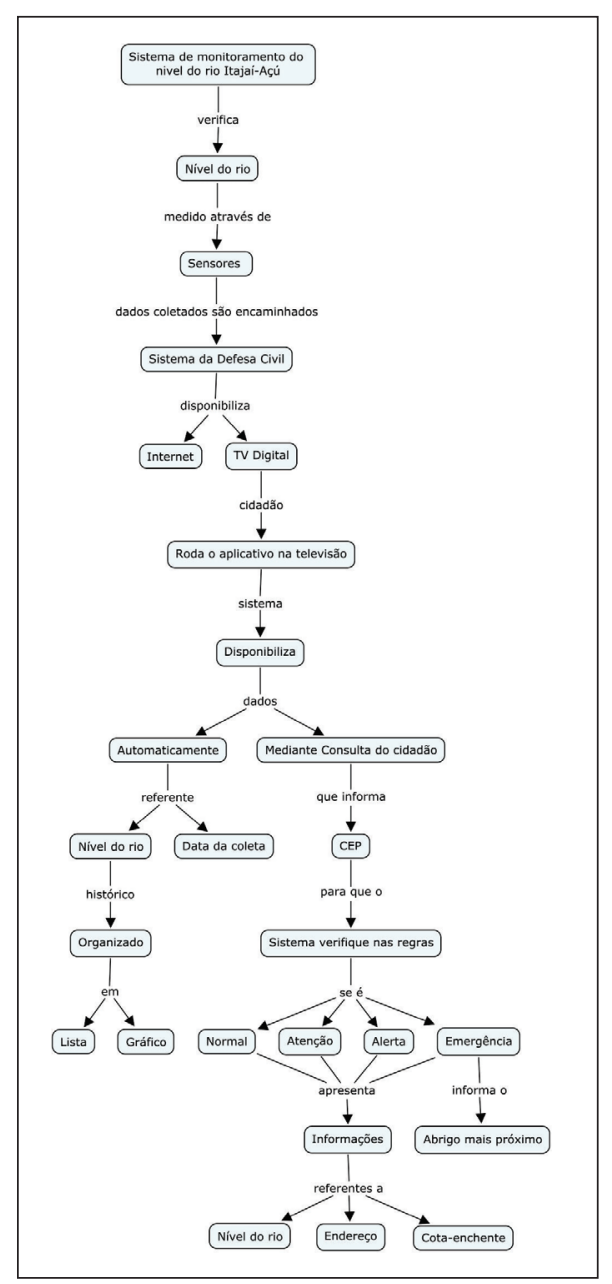

FIGURA 4 - Mapa Conceitual do Serviço de Governo Proposto Para a TV Digital

FONTE: Elaborada pelos próprios autores. 


\section{Conclusão e Trabalhos Futuros}

As iniciativas de governo eletrônico devem primar sempre o atendimento das reais necessidades dos cidadãos, priorizando o fornecimento de serviços integrados e seguros em um ambiente interativo.

Em períodos de enchente, o único meio de comunicação existente é o rádio ou a televisão. Nesta situação, um serviço tal como foi sugerido neste artigo seria fundamental para auxiliar a população blumenauense.

Por meio dos mapas conceituais, foi possível representar todo o conhecimento envolvido quando na disponibilização de um serviço de governo via TV Digital. Assim, foi possível comprovar assim a eficiência na organização e representação do conhecimento envolvido neste domínio de aplicação.

Dentre as diversas vantagens apontadas para a utilização de mapas conceituais para este fim, colocamos ênfase na simplicidade de organização e entendimento da estrutura de conhecimento.

Trabalhos futuros podem envolver diferentes processos de construção de representações relativas a organização deste mesmo serviço sugerido. Ainda, pode-se buscar um maior detalhamento com relação aos benefícios em se utilizar a cartografia cognitiva.

\section{Referências}

ALMEIDA, V.D.O.; MOREIRA, M.A. Mapas Conceituais no Auxílio à Aprendizagem Significativa de Conceitos da Óptica Física. Revista Brasileira de Ensino de Física, v. 30, n. 4, p. 17-25, 2008. Disponível em: <http://www.scielo.br/pdf/rbef/v30n4/v30n4a09.pdf> Acesso em: 29 jun. 2015.

AMORETTI, M.S.M. Protótipos e Estereótipos: aprendizagem de conceitos Mapas Conceituais: experiência em Educação a Distância. Revista Informática na Educação: teoria e prática, v. 4, n. 2, p. 49-5, 2001. Disponível em: <http://www.espie.cinted.ufrgs.br/ dsbit/trimestre2/margarete/Leituras/ Mapas_Conceituais_SusanaAmoretti.pdf> Acesso em: 9 jun. 2011.

AMORETTI, M.S.M.; TAROUCO, L.M.R. Mapas Conceituais: modelagem colaborativa do conhecimento. Informática na educação: teoria e prática, v. 3, n. 1, p. 1-6, 2008. Disponível em: <http://seer.ufrgs.br/index.php/InfEducTeoriaPratica/article/view/6412> Acesso em: 1 jun. 2011.

BRASIL. Ministério do Planejamento, OrçamentoeGestão. Secretaria de Logísticae Tecnologia da informação. Departamento de Governo Eletrônico. Programa de Governo Eletrônico. Brasília, 2010. Disponível em: <http://www.governoeletronico.gov.br/o-gov.br> Acesso em: 29 jul. 2010.

CAÑAS, A.J. et al. CmapTools: A knowledge modeling and sharing environment. Concept maps: Theory, methodology, technology. In: INTERNATIONAL CONFERENCE ON CONCEPT MAPPING, 1., 2004, Pamplona. Proceedings. Pamplona: CMC, 2004. V. 1, p. 125-133. Disponível em: < http://citeseerx. ist.psu.edu/viewdoc/download?doi=10.1.1.132.6645\&amp;rep=rep1\&amp;type=pdf $>$ Acesso em: 14 abr. 2011. 
CODINA, L. Mapas Conceptuales y Mapas Mentales: composición, funciones y principios de calidad. Barcelona: UPF, Grupo DigiDoc, 2010.

CORRADI, F.M. et al. Nós, Links e Redes. Revista de Biologia e Ciências da Terra, v. 1, n. 1, 2001. Disponível em: <http://eduep.uepb.edu.br/rbct/sumarios/pdf/nos.pdf> Acesso em: 29 jun. 2015.

DORON, R.; PAROT, F. Dicionário de Psicologia. São Paulo: Ed. Ática, 1998.

DUIT, R. On the role of analogies and metaphors in learning science. Science Education, New York, v. 75, n. 6, p. 649-672, 1991.

DUPUY, J.-P. Nas Origens das Ciências Sociais. São Paulo: Ed. da Universidade Estadualista, 1996.

FIALHO, F.A.P. Psicologia das Atividades Mentais: introdução às ciências da cognição. Florianópolis: Ed. Insular, 2011.

GARDNeR, H. A Nova Ciência da Mente: uma história da revolução cognitiva. São Paulo: Ed. da Universidade de São Paulo, 1995.

HOUAISS, A. et al. Dicionário Houaiss da Língua Portuguesa. 1. ed. Rio de Janeiro: Objetiva, 2009. IHMC. Joseph D. Novak. Pensacola, FI: IHMC Florida Institure dor Human \& Machine Cognition, 2011. Disponível em: <http://www.ihmc.us/groups/jnovak/> Acesso em: 05 jun. 2011.

LIMA, G.Â.B.O. Mapa Conceitual Como Ferramenta Para Organização do Conhecimento em Sistema de Hipertextos e Seus Aspectos Cognitivos. Perspectivas em Ciência da Informação, Belo Horizonte, v. 9, n. 2, p. 134-145, 2004. Disponível em: < http://portaldeperiodicos.eci.ufmg.br/index.php/pci/ article/view/355/164> Acesso em: 9 jun. 2011.

LUGER, G.F. Cognitive Science: The science of intelligent systems. San Diego: Academic Press, 1994. MARSHAL, T.H. Cidadania, Classe Social e Status. Rio de Janeiro: Zahar, 1967.

MATLIN, M.W. Psicologia Cognitiva. 5. ed. Rio de Janeiro: LTC, 2004.

MEADOWS, D.L. et al. Dynamics of Growth in a Finite World. Cambridge: Wright-Allen Press, 1974.

MOREIRA, M.A. Mapas Conceptuales y Aprendizaje Significativo en Ciencias. Revista Chilena de Educación Científica, v. 4, n. 2, p. 38-44, 2005. Disponível em: <http://vargas.me.gob.ve/media/ contenidos/2008/d_1001_66.pdf> Acesso em: 1 jun. 2011.

MOREIRA, M.A.; BUCHWEITZ, B. Mapas Conceituais: instrumentos didáticos, de avaliação e de análise de currículo. São Paulo: Moraes, 1987. 
MOREIRA, M.A.; MASINI, E.F.S. Aprendizagem Significativa: a teoria de David Ausubel. 2. ed. São Paulo: Centauro, 2002.

NHS. ABC of Knowledge Management. Londres: [s.n.], 2005.

NOVAK, J.D. Uma Teoria de Educação. São Paulo: Pioneira, 1981.

NOVAK, J.D.; GOWIN, D. B. Aprender a Aprender. 2. ed. Lisboa: Plátano, 1999.

OKADA, A. Cartografia Cognitiva: mapas do conhecimento para pesquisa, aprendizagem e formação docente. Cuiabá: Kcm, 2008.

PELIZZARI, A. et al. Teoria da Aprendizagem Significativa Segundo Ausubel. Revista Psicologia Educação e Cultura, Vila Nova de Gaia, PO, v. 2, n. 1, p. 37-42, 2001. Disponível em: <http://files.percursosdosaber.webnode.pt/200000019-5b51c5c4b8/teoria_da_aprendizagem_signifi._Ausubel.pdf> Acesso em: 6 jun. 2011.

SANCHEZ, O.A. O Governo Eletrônico no Estado de São Paulo. São Paulo: [s.n.], 2003. (Série Didática, n. 6) Disponível em: <http://www.cedec.org.br/files_pdf/DIDATI7-GOV\%20ELETR.pdf> Acesso em: 21 fev. 2009.

SENGE, P.M. A Quinta Disciplina: arte e prática da organização de aprendizagem. 12. ed. São Paulo: Nova Cultural, 1990.

SOURBATI, M. Digital television, online connectivity and electronic service delivery: implications for communications policy (and research). Media, Culture \& Society, Londres, v. 26, n. 4, p. 585-590, 2004.

SVEIBY, K.E. A Nova Riqueza das Organizações: gerenciando e avaliando patrimônios de conhecimento. 7. ed. Rio de Janeiro: Campus, 1998.

Submetido para avaliação em 24 de junho de 2011.

Aprovado para publicação em 10 de junho de 2015.

Paloma Maria Santos - Universidade Federal de Santa Catarina, Florianópolis, BR-SC. E-mail: pmariasantos@yahoo. com.br

Airton Zancanaro - Universidade Federal de Santa Catarina, Florianópolis, BR-SC. E-mail: airtonza@gmail.com Neri dos Santos - Universidade Federal de Santa Catarina, Florianópolis, BR-SC. E-mail: neri@egc.ufsc.br 